
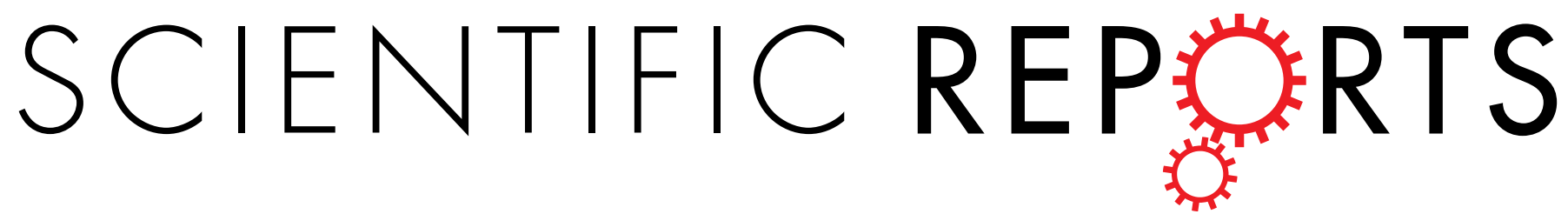

\title{
OPEN
}

Received: 03 March 2015

Accepted: 24 April 2015

Published: 29 May 2015

\section{Detection of Nitro-Based and Peroxide-Based Explosives by Fast Polarity-Switchable Ion Mobility Spectrometer with lon Focusing in Vicinity of Faraday Detector}

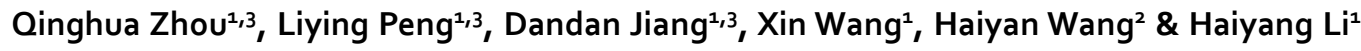

Ion mobility spectrometer (IMS) has been widely deployed for on-site detection of explosives. The common nitro-based explosives are usually detected by negative IMS while the emerging peroxide-based explosives are better detected by positive IMS. In this study, a fast polarityswitchable IMS was constructed to detect these two explosive species in a single measurement. As the large traditional Faraday detector would cause a trailing reactant ion peak (RIP), a Faraday detector with ion focusing in vicinity was developed by reducing the detector radius to $3.3 \mathrm{~mm}$ and increasing the voltage difference between aperture grid and its front guard ring to $591 \mathrm{~V}$, which could remove trailing peaks from RIP without loss of signal intensity. This fast polarity-switchable IMS with ion focusing in vicinity of Faraday detector was employed to detect a mixture of $10 \mathrm{ng}$ 2,4,6-trinitrotoluene (TNT) and $50 \mathrm{ng}$ hexamethylene triperoxide diamine (HMTD) by polarityswitching, and the result suggested that $[\mathrm{TNT}-\mathrm{H}]^{-}$and $[\mathrm{HMTD}+\mathrm{H}]^{+}$could be detected in a single measurement. Furthermore, the removal of trailing peaks from RIP by the Faraday detector with ion focusing in vicinity also promised the accurate identification of $\mathrm{KClO}_{4}, \mathrm{KNO}_{3}$ and $\mathrm{S}$ in common inorganic explosives, whose product ion peaks were fairly adjacent to RIP.

Ion mobility spectrometer (IMS) is a well-known tool for gas-phase ion separation based on the differences of compounds in reduced mass, charge, and collisional cross section. Much of its popularity is derived from its successful application in the detection of conventional explosives including 2,4,6-trinitrotoluene (TNT), cyclo-1,3,5-trimethylene-2,4,6-trinitramine (RDX), pentaerythritol tetranitrate (PETN), ammonium nitrate fuel oil (ANFO) and so on ${ }^{1-6}$, which are usually detected by negative ion molecules. In recent years, the peroxide-based explosives, such as triacetone triperoxide (TATP) and hexamethylene triperoxide diamine (HMTD), have been implicated in the terrorist activities due to their easy prepara$\operatorname{tion}^{7,8}$. These explosives were better detected by positive ion mode IMS ${ }^{9-11}$. Therefore, to quickly and fully identify different explosive species, a fast polarity-switchable IMS is highly desirable.

The most crucial part of an IMS is its drift tube, which is normally made of a stack of metal guard rings separated by insulated rings ${ }^{12-16}$. At present, two commonly used drift tubes are constructed from thick ${ }^{13-15}$ and thin ${ }^{16,17}$ metal guard rings, respectively. With the use of these two types of drift tubes, Soppart et al. observed that the drift tube with thin metal guard rings possessed more than twice

${ }^{1}$ Key Laboratory of Separation Science for Analytical Chemistry, Dalian Institute of Chemical Physics, Chinese Academy of Sciences, Dalian, Liaoning, 116023, People's Republic of China. ${ }^{2}$ Jiangsu Province Institute of Quality and Safety Engineering, Nanjing, Jiangsu, 210046, People's Republic of China. 3University of Chinese Academy of Sciences, Beijing, 100049, People's Republic of China. Correspondence and requests for materials should be addressed to H.L. (email: hli@dicp.ac.cn) 


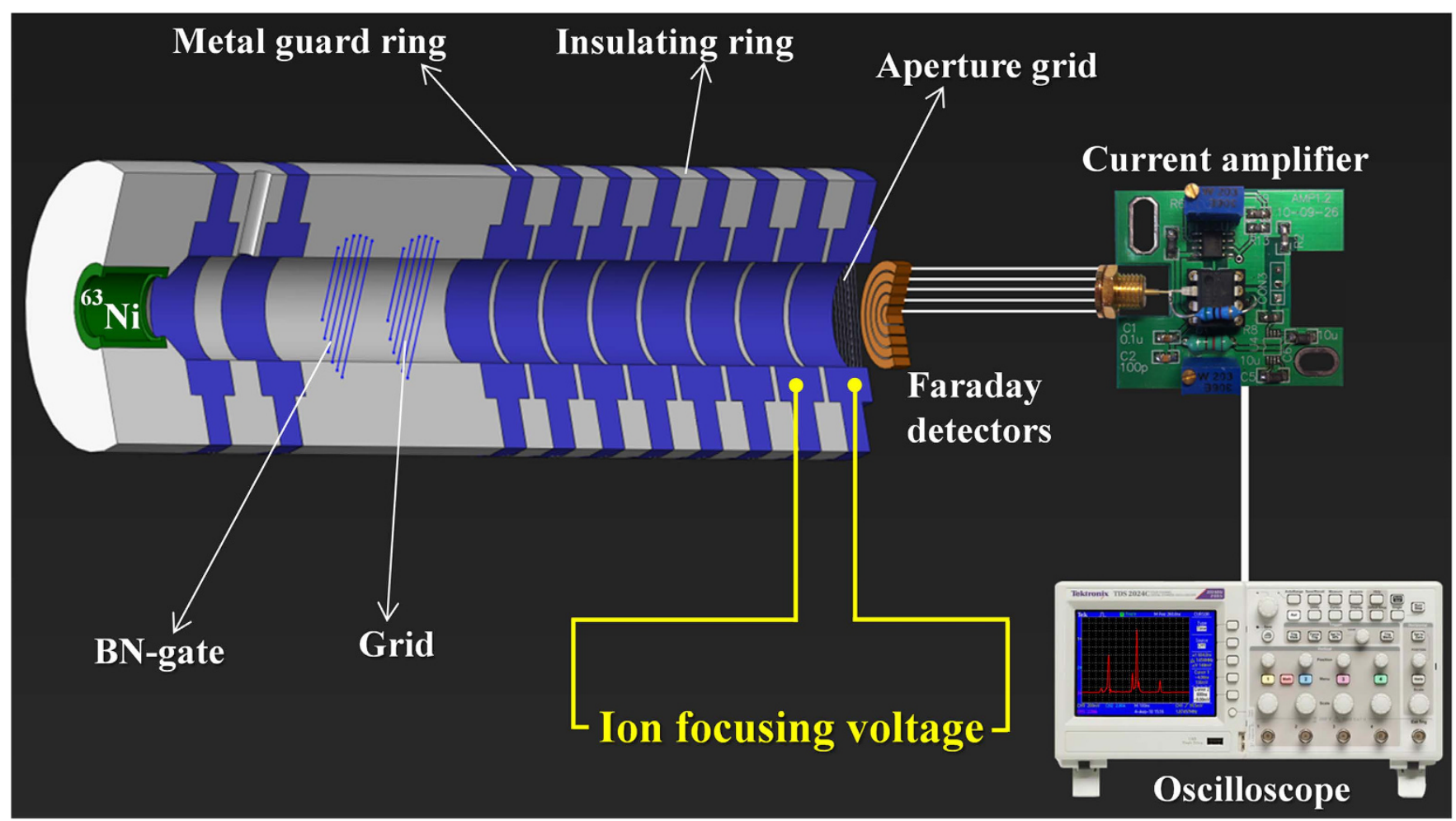

Figure 1. Schematic drawing of ion mobility spectrometer (IMS) constructed with thick metal guard rings.

the signal amplitude at a highly increased resolution ${ }^{12}$. Whereas in our polarity-switching test, due to the effect of accumulated charges, a much longer time was needed for the drift tube with thin metal guard rings to recover its IMS signal after polarity-switching (see supplementary information Fig. S1), which indicates that drift tube with thick metal guard rings might be more suitable for constructing a polarity-switchable IMS. However, Liu et al. suggested that the homogeneity of electric field in the drift tube was decreased when the thickness of metal guard rings was increased ${ }^{18}$; the inhomogeneity in the electric field could cause divergence of drift velocity for the same kind of ions ${ }^{12}$, which would probably broaden the peak widths and lead to lower resolving power for the IMS.

To improve the resolving power of an IMS, the radial distribution of ions in the drift tube is of valuable information, as it essentially determines the IMS spectrum. Up to date, several works have been carried out to investigate the radial distribution of ions in the drift tube with different ion sources ${ }^{19-24}$. Among these, Eiceman and Davila et al. experimentally measured the radial ion density profiles in the ${ }^{63} \mathrm{Ni}$ ionization IMS using a charge accumulation IonCCD detector with imaging capability of 2126 pixels at each $21 \mu \mathrm{m}$ width, suggesting that the ion density was highest at the center of detector while declined radially ${ }^{19,21}$. However, this result was in contradiction with the work by Karpas et al. ${ }^{24}$ in which the ion density at the center of detector was lower than its outer parts. Tabrizchi et al. ${ }^{23}$ and Kwasnik et al. ${ }^{20}$ measured the radial ion density profiles in the drift tube using corona discharge ion source, and the ion density profiles were qualitatively similar to the observation of drift tube using electrospray ionization ion source by Hill et al. ${ }^{22}$. In practice, $\mathrm{Wu}$ et al. achieved an improvement of IMS resolving power by decreasing the internal diameter of aperture grid $^{25}$; but reducing the size of a Faraday detector could cause a drop of IMS signal synchronously ${ }^{12,13}$. In addition, the resolving power and peak shape for IMS are significantly depended on the construction of the aperture grid as well as the voltage applied ${ }^{26,27}$.

In this study, a fast polarity-switchable IMS was built with thick metal guard rings. The ion mobility spectra and the ion density profiles were carefully studied using five concentric Faraday detectors. Based on the ion density profiles with the voltage difference between aperture grid and its front guard ring $(\Delta \mathrm{V})$, a Faraday detector with ion focusing in vicinity was developed to boost the IMS signal while removing the tailing peaks from the reactant ion peak (RIP). Finally, the analytical performances of this IMS apparatus for explosives detection were demonstrated by the detection of a mixture of TNT and HMTD via fast polarity-switching between negative and positive ion modes in a single measurement. In addition, the detection of $\mathrm{KClO}_{4}, \mathrm{KNO}_{3}$ and $\mathrm{S}$ in common inorganic explosives, such as black powder was achieved. 


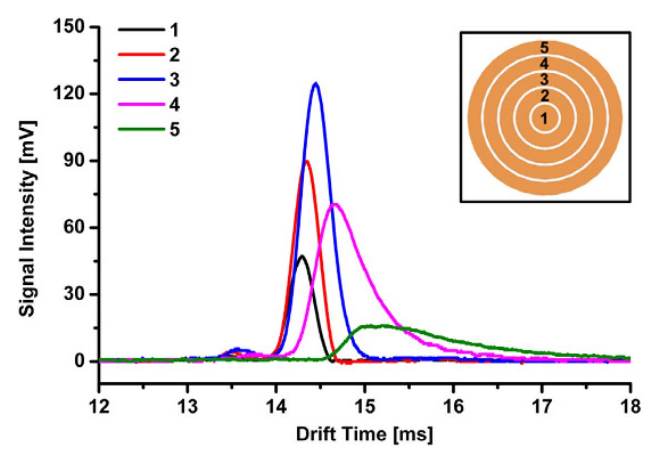

Figure 2. Ion mobility spectra of reactant ion peak (RIP) obtained by five different concentric detectors, the voltage difference between aperture grid and its front guard ring $(\Delta \mathrm{V})$ was $197 \mathrm{~V}$.

\begin{tabular}{|l|c|c|c|c|}
\hline \multicolumn{1}{|c|}{ Detector } & $\begin{array}{c}\text { Drift } \\
\text { Time }\end{array}$ & Height & FWHM & Ion density \\
\hline number & $/ \mathrm{ms}$ & $/ \mathrm{mV}$ & $/ \mathrm{ms}$ & \\
\hline 1 & 14.29 & 47 & 0.32 & 2.24 \\
\hline 2 & 14.33 & 90 & 0.34 & 1.32 \\
\hline 3 & 14.45 & 125 & 0.39 & 1.26 \\
\hline 4 & 14.64 & 70 & 0.66 & 1.02 \\
\hline 5 & 15.02 & 16 & 1.44 & 0.40 \\
\hline
\end{tabular}

Table 1. Characteristics of RIPs at five different concentric detectors.

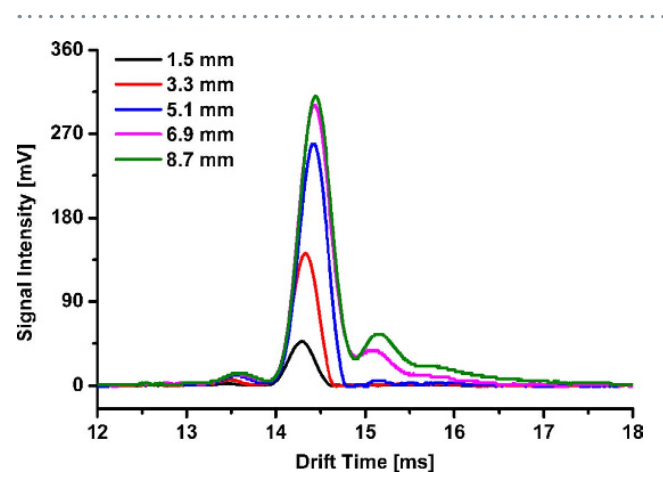

Figure 3. Ion mobility spectra of RIP at the traditional Faraday detectors with radiuses of 1.5, 3.3, 5.1, 6.9, and $8.7 \mathrm{~mm}$, respectively, $\Delta \mathrm{V}=197 \mathrm{~V}$.

\section{Methods}

An IMS apparatus with $\mathrm{BN}$-grid structure ${ }^{28}$ was built using the stack design with thick stainless steel guard rings ( $18 \mathrm{~mm}$ i.d., $8 \mathrm{~mm}$ thickness) and Teflon insulating rings ( $18 \mathrm{~mm}$ i.d., $1 \mathrm{~mm}$ thickness), schematically shown in Fig. 1. A ${ }^{63} \mathrm{Ni}$ foil was used as the ion source in a cylinder $(10 \mathrm{~mm}$ length, $10 \mathrm{~mm}$ diameter). The drift region was $79 \mathrm{~mm}$ in length, and a voltage difference of $197 \mathrm{~V}$ was applied between the two adjacent guard rings. The aperture grid was made of stainless steel screen $(0.2 \mathrm{~mm}$ thickness, 40 mesh), $1 \mathrm{~mm}$ in front of the Faraday detector. It should be mentioned that the voltage difference between the aperture grid and its front guard ring, $\Delta \mathrm{V}$, could be adjusted from 197 to $1379 \mathrm{~V}$, while the voltage difference between the aperture grid and Faraday detector was kept constant at $355 \mathrm{~V}$. The gating voltage difference applied on the BN gate was $220 \mathrm{~V}$, and the gating pulse width was $300 \mu$ s. Additionally, a different IMS apparatus was built to merely detect the mixture of TNT and HMTD via fast polarity-switching between the negative and positive ion modes, as a comparative test; this apparatus was similar to that in Fig. 1, except the following parameters: the stack of thin stainless steel guard rings $(18 \mathrm{~mm}$ i.d., $1 \mathrm{~mm}$ thickness) with Teflon insulating rings ( $18 \mathrm{~mm}$ i.d., $6 \mathrm{~mm}$ thickness), and the drift region of $67.5 \mathrm{~mm}$ in length. When the polarity-switching was carried out, a recovery time of $2 \mathrm{~s}$ and $20 \mathrm{~s}$ was required for the IMS with the thick and thin metal guard rings, respectively (see supplementary information Fig. S1). 


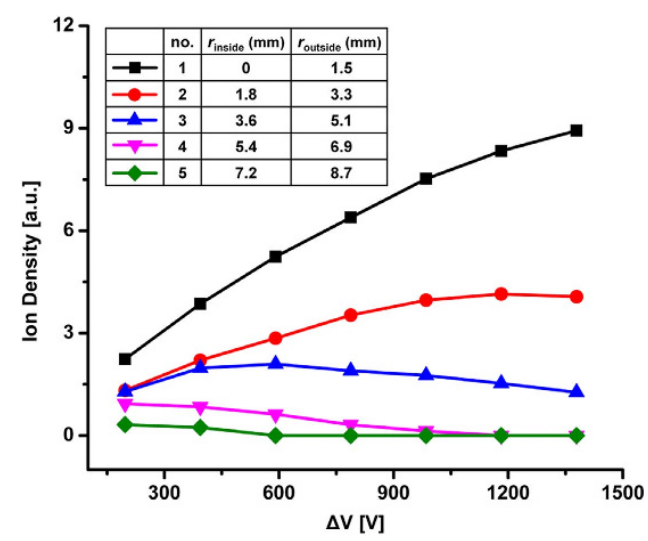

Figure 4. Densities of reactant ion at five different concentric detectors with the increase of $\Delta \mathrm{V}$ from 197 to $1379 \mathrm{~V}$. Inside radius of the detector: $r_{\text {inside }}$, outside radius of the detector: $r_{\text {outside }}$.
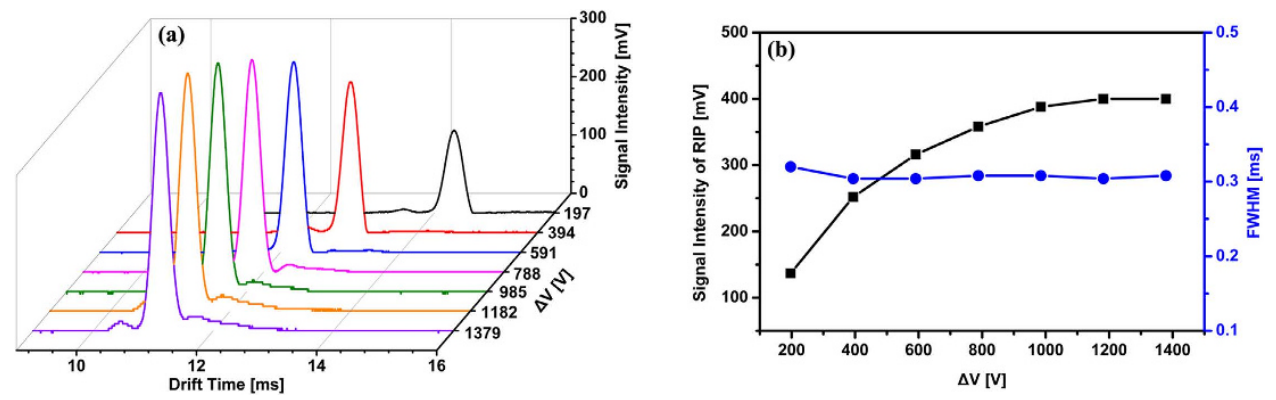

Figure 5. (a) Ion mobility spectra of RIP by increasing $\Delta \mathrm{V}$ from 197 to $1379 \mathrm{~V}$; (b) the RIP signal intensity and full width at half maximum (FWHM) versus $\Delta \mathrm{V}$ using the reduced Faraday detector (radius of $3.3 \mathrm{~mm}$ ).

To investigate the radial distribution of ions in the drift tube with thick metal guard rings at $20^{\circ} \mathrm{C}$, we divided a traditional Faraday detector (radius of $8.7 \mathrm{~mm}$ ) into five detectors, including a center plate (No.1, radius of $1.5 \mathrm{~mm}$ ) and four concentric rings (No.2 5, ring width of $1.5 \mathrm{~mm}$ each), which were mounted on an insulated support and separated from each other by a space of $0.3 \mathrm{~mm}$, schematically shown as the inset in Fig. 2. The ion currents from the detectors were amplified by the same preamplifier and were acquired by an oscilloscope (Tektronix TDS 2024C). When a specific Faraday detector was connected to the preamplifier for measurement, the other ones were connected to the ground.

Clean air, filtrated by silica gel, activated carbon and 13X molecular sieve traps, was used for the carrier and drift gases, with a flow rate of 300 and $500 \mathrm{~mL} \mathrm{~min}^{-1}$, respectively. The moisture level of purified air was kept below 1 ppm.

$50 \mu \mathrm{g} \mu \mathrm{L}^{-1} \mathrm{KClO}_{4}, 50 \mu \mathrm{g} \mu \mathrm{L}^{-1} \mathrm{KNO}_{3}$, and $0.05 \mu \mathrm{g} \mu \mathrm{L}^{-1} \mathrm{~S}$ standard stock solutions were prepared by weighing and dissolving their pure samples in the distilled water or acetone. $1 \mu \mathrm{g}_{\mu} \mathrm{L}^{-1} \mathrm{TNT}$ standard stock solution was purchased from AccuStandard, Inc. (New Haven, CT). HMTD was synthesized in our laboratory by referring to the previous work ${ }^{29}$, and a $1 \mu \mathrm{g} \mu \mathrm{L}^{-1}$ stock solution was prepared by weighing and dissolving of HMTD in acetone. Test samples were obtained by successive dilution of their standard stock solutions with methanol or acetone, and were introduced into the IMS apparatus at $100^{\circ} \mathrm{C}$ by a thermal desorber ${ }^{1,30}$ at $180^{\circ} \mathrm{C}$. Firstly, $1 \mu \mathrm{L}$ of sample solution was deposited on a Teflon-coated fiberglass swab, and then the swab was inserted into the thermal desorber after the solvent was evaporated. The carrier gas passed through the desorber and sent the vapor sample into the IMS apparatus for analysis.

Safety consideration: HMTD is an extremely dangerous substance which may lead to severe explosion, so the synthesis and treatment of HMTD should be only carried out by authorised and highly skilled professional personnel in small quantities, using appropriate protection measures (reinforced gloves and goggles, explosion-proof vessels, etc.).

\section{Results and Discussion}

Ion radial distribution and peak profiles. Figure 2 illustrates the ion mobility spectra of negative RIPs at five concentric detectors in the drift tube with thick metal guard rings, from which we summarize the peak characteristics in Table 1. Ion density, defined as the division of the area of RIP by the area of 

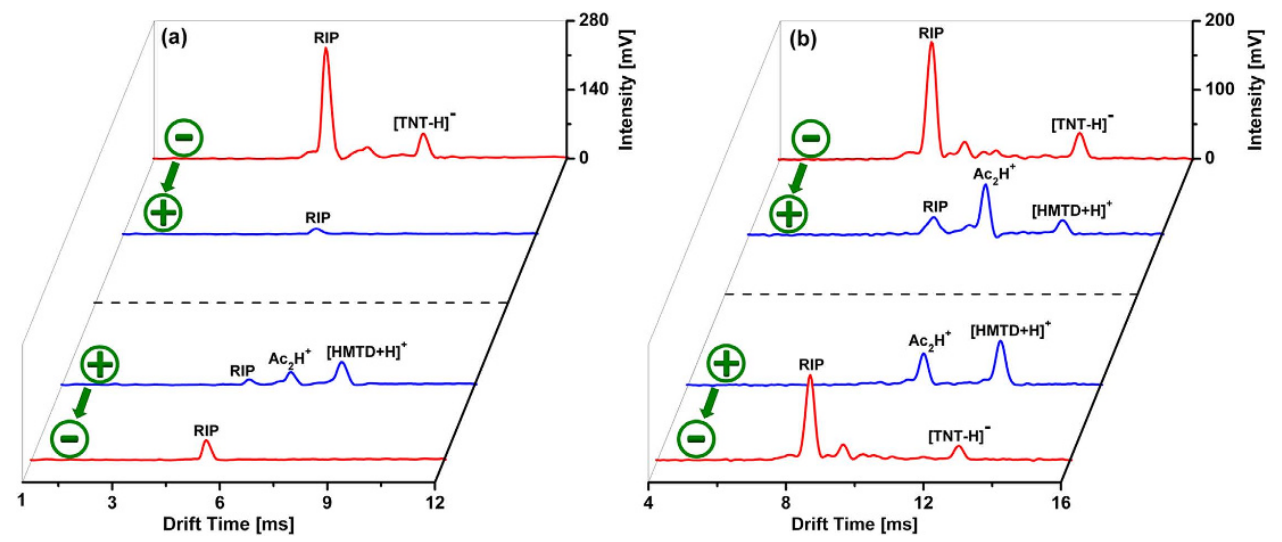

Figure 6. Ion mobility spectra of an explosive mixture including $10 \mathrm{ng}$ TNT and $50 \mathrm{ng}$ HMTD obtained by polarity-switching IMS with (a) thin and (b) thick metal guard rings. The $\mathrm{Ac}_{2} \mathrm{H}^{+}$ion peak in the positive spectrum comes from the acetone used to dissolve HMTD.

(a)

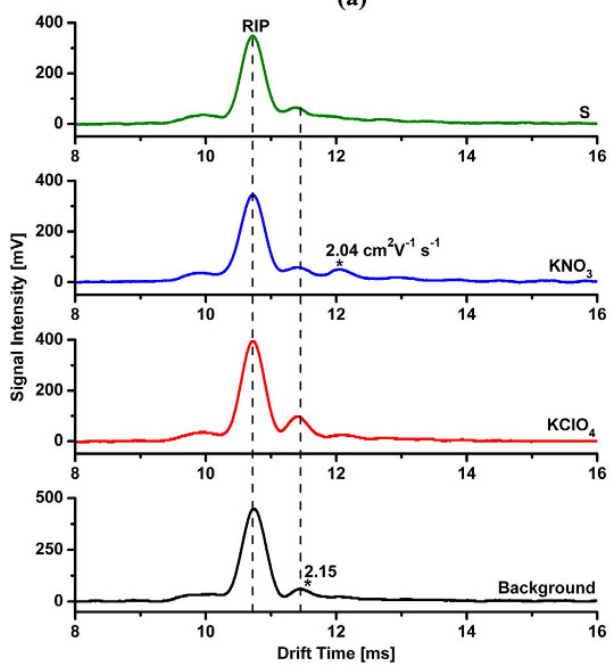

(b)

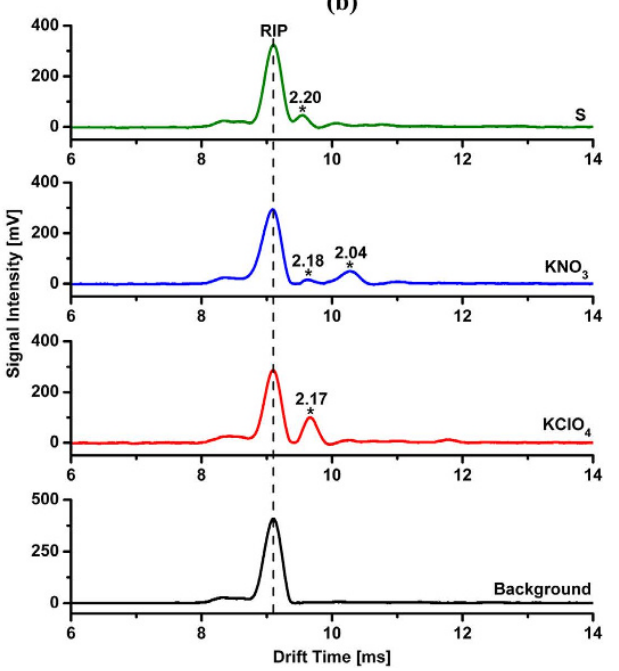

Figure 7. Ion mobility spectra of $600 \mathrm{ng} \mathrm{KClO}_{4}, 4 \mathrm{ng} \mathrm{KNO}_{3}$ and $2 \mathrm{ng} \mathrm{S}$ using (a) large traditional Faraday detector (radius of $8.7 \mathrm{~mm}$ ) and (b) Faraday detector with ion focusing in vicinity. To facilitate the evaporation of these compounds during the thermal desorption introduction, $15 \mu \mathrm{L}$ of $3 \% \mathrm{H}_{3} \mathrm{PO}_{4}$ solution was added into $1 \mathrm{~mL}$ of their test solutions.

detector, is maximal at the central detector, and then gradually declines for the detector away from the central axis of drift tube (the distance was defined as $d_{\mathrm{x}}$ ), which agrees to the previous works by Eiceman and Davila ${ }^{19,21}$. It is notable that the drift time of RIP shifts to the longer one, and the full width at half maximum (FWHM) of RIP is widened as $d_{\mathrm{x}}$ is increased. Especially, there are obvious trailing edges appeared for the RIP obtained by detector \#4 and \#5, which should be attributed to the inhomogeneity of drift electric field near the inwall of drift tube (see supplementary information Fig. S2).

Traditional Faraday detector. Figure 3 shows the profiles of RIPs at the traditional Faraday detectors with different radiuses of $1.5,3.3,5.1,6.9$, and $8.7 \mathrm{~mm}$. The RIP intensity at the Faraday detector with radius of $1.5 \mathrm{~mm}$ is $47 \mathrm{mV}$, which can be improved by factors of 3, 5.5 and 6.4 when the radius of Faraday detector is increased to $3.3,5.1$ and $6.9 \mathrm{~mm}$, respectively; while no prominent improvement of RIP intensity can be observed by further increasing the radius from 6.9 to $8.7 \mathrm{~mm}$. However, when the radius of Faraday detector is larger than $3.3 \mathrm{~mm}$, RIP appears with trailing peaks; from the results in Fig. 2, it can be concluded that these trailing peaks should be produced by the ions of drift trajectories far away from the central axis of drift tube, reaching the Faraday detector with longer drift times.

According to Fig. 3, to obtain the RIP without trailing peaks, it is appropriate to reduce the radius of traditional Faraday detector to $3.3 \mathrm{~mm}$. Nevertheless, comparing to the larger one (radius of $8.7 \mathrm{~mm}$ ), 
the RIP intensity at this reduced Faraday detector is decreased by more than $50 \%$, so it is desirable to improve its signal intensity.

Faraday detector with ion focusing in vicinity. As shown in Fig. 4, we measured the density of reactant ion at five concentric detectors with increasing $\Delta \mathrm{V}$ from 197 to $1379 \mathrm{~V}$, where $\Delta \mathrm{V}$ was the voltage difference between aperture grid and its front guard ring. Interestingly, at detector \#1, the ion density increases constantly with $\Delta \mathrm{V}$; at detector $\# 2$ and $\# 3$, the ion density initially increases then decays at $1182 \mathrm{~V}$ and $394 \mathrm{~V}$, respectively; at detector $\# 4$ and $\# 5$, the ion density decays with increasing of $\Delta \mathrm{V}$. To understand these phenomena, we simulated the ion trajectories in drift tube while $\Delta \mathrm{V}$ was increased from 197 to $1379 \mathrm{~V}$ using Simion 8.0 (see supplementary information Fig. S3). The results indicate that ion focusing exists near the aperture grid, and its strength is positively correlated to $\Delta \mathrm{V}$. Thus, combining the ion focusing to the reduced Faraday detector (radius of $3.3 \mathrm{~mm}$ ), the intensity of IMS signal can be significantly enhanced.

As presented in Fig. 5a, we obtained a series of ion mobility spectra using a Faraday detector with radius of $3.3 \mathrm{~mm}$ by increasing $\Delta \mathrm{V}$ from 197 to $1379 \mathrm{~V}$. By plotting the RIP signal intensity and FWHM versus $\Delta \mathrm{V}$ in Fig. $5 \mathrm{~b}$, it can be found that increasing $\Delta \mathrm{V}$ indeed brings a prominent increase for RIP signal intensity, while the FWHMs of RIP remain at about $0.3 \mathrm{~ms}$. Whereas, when $\Delta \mathrm{V}$ is higher than $591 \mathrm{~V}$, the ion focusing is so strong that those ions near the inwall of drift tube can be focused to the Faraday detector, leading to the trailing peaks for RIP again, as shown in Fig. 5a.

Therefore, a Faraday detector with ion focusing in vicinity (radius of $3.3 \mathrm{~mm}, \Delta \mathrm{V}$ of $591 \mathrm{~V}$ ) was selected to produce RIP without trailing peaks, and its intensity was comparable to that obtained by the traditional Faraday detector with radius of $8.7 \mathrm{~mm}$ (see supplementary information Fig. S4).

Detection of TNT and HMTD in a single measurement. To demonstrate the ability of proposed IMS with thick metal guard rings for the detection of nitro-based and peroxide-based explosives in a single measurement, an explosive mixture, consisting of $10 \mathrm{ng}$ TNT (nitro-based explosive, detected by negative ions) and $50 \mathrm{ng}$ HMTD (peroxide-based explosive, detected by positive ions), was chosen to be detected by the polarity-switching method. $1 \mu \mathrm{L}$ of this explosive mixture was firstly deposited on a Teflon-coated fiberglass swab; after the solvent was evaporated, the swab was inserted into the thermal desorber for $15 \mathrm{~s}$ and the polarity-switching of IMS was carried out at the $7^{\text {th }} \mathrm{s}$. The mixture was also detected by the IMS with thin metal guard rings for a comparative test.

As shown in Fig. 6a, for the IMS with thin metal guard rings, when the polarity was switched from negative ion mode to positive ion mode, only $[\mathrm{TNT}-\mathrm{H}]^{-}$in the negative spectrum could be detected, while no HMTD signal appeared in the positive spectrum. Similarly, when the polarity was switched from positive to negative, only $[\mathrm{HMTD}+\mathrm{H}]^{+}$in the positive spectrum could be detected, while no TNT signal appeared in the negative spectrum. Conversely, as shown in Fig. 6b, when the mixture sample of TNT and HMTD was detected using IMS with thick metal guard rings, no matter what polarity-switching sequence it was, $[\mathrm{TNT}-\mathrm{H}]^{-}$in the negative spectrum and $[\mathrm{HMTD}+\mathrm{H}]^{+}$in the positive spectrum could be both detected, achieving the detection of TNT and HMTD in a single measurement.

Identification of inorganic explosives. In the last two decades, inorganic explosives have been employed in many terrorist attacks ${ }^{31}$, due to their unrestricted availability and low cost. Using IMS to identify the typical components in inorganic explosives, such as $\mathrm{KClO}_{4}, \mathrm{KNO}_{3}$ and $\mathrm{S}$, it is found that their product ion peaks are fairly closed to the RIP ${ }^{30}$, so a RIP without trailing peaks is required to accomplish their identifications. To demonstrate the capacity of proposed IMS with ion focusing in vicinity of Faraday detector for inorganic explosives detection, $600 \mathrm{ng} \mathrm{KClO}_{4}, 4 \mathrm{ng} \mathrm{KNO}_{3}$ and $2 \mathrm{ng} \mathrm{S}$ were chosen to be detected in the negative ion mode. To facilitate the evaporation of these compounds during the thermal desorption introduction, $15 \mu \mathrm{L}$ of $3 \% \mathrm{H}_{3} \mathrm{PO}_{4}$ solution was added into $1 \mathrm{~mL}$ of their test solutions ${ }^{30}$.

As a comparison test in Fig. 7a, with the large traditional Faraday detector (radius of $8.7 \mathrm{~mm}$ ), the RIP is accompanied with a trailing peak (reduced mobility $K_{0}=2.15 \mathrm{~cm}^{2} \mathrm{~V}^{-1} \mathrm{~s}^{-1}$ ), which are seriously overlapped with the ion peaks of $\mathrm{KClO}_{4}$ and $\mathrm{S}$, so only $\mathrm{KNO}_{3}$ could be identified by the ion peak with $K_{0}$ of $2.04 \mathrm{~cm}^{2} \mathrm{~V}^{-1} \mathrm{~s}^{-1}$. Conversely, using the Faraday detector with ion focusing in vicinity, the trailing peak of RIP is disappeared, achieving the reliable identification of ion peaks for $\mathrm{KClO}_{4}\left(K_{0}=2.17 \mathrm{~cm}^{2} \mathrm{~V}^{-1} \mathrm{~s}^{-1}\right)$, $\mathrm{KNO}_{3}\left(K_{0}=2.18\right.$ and $\left.2.04 \mathrm{~cm}^{2} \mathrm{~V}^{-1} \mathrm{~s}^{-1}\right)$ and $\mathrm{S}\left(K_{0}=2.20 \mathrm{~cm}^{2} \mathrm{~V}^{-1} \mathrm{~s}^{-1}\right)$, as shown in Fig. $7 \mathrm{~b}$. What is more, the peak intensities in Fig. $7 \mathrm{~b}$ are comparable to that in Fig. $7 \mathrm{a}$, suggesting that the use of Faraday detector with ion focusing in vicinity would not cause visible loss of detection sensitivity.

\section{Conclusions}

In this work, we developed a fast polarity-switchable ion mobility spectrometer with ion focusing in vicinity of Faraday detector for explosives detection. By fast polarity-switching, nitro-based explosives such as TNT and peroxide-based explosives such as HMTD could be detected in a single measurement, which broadened the detectable explosive species. Furthermore, the use of Faraday detector with ion focusing in vicinity could remove trailing peaks from RIP, providing a simple method to accurately identify the typical components in inorganic explosives whose product ion peaks were fairly adjacent to RIP, without loss of detection sensitivity. 


\section{References}

1. Cheng, S. et al. Dopant-assisted negative photoionization ion mobility spectrometry for sensitive detection of explosives. Anal. Chem. 85, 319-326 (2013).

2. Khayamian, T., Tabrizchi, M. \& Jafari, M. T. Analysis of 2,4,6-trinitrotoluene, pentaerythritol tetranitrate and cyclo-1,3,5trimethylene-2,4,6-trinitramine using negative corona discharge ion mobility spectrometry. Talanta 59, 327-333 (2003).

3. Kanu, A. \& Hill, H. H. Identity confirmation of drugs and explosives in ion mobility spectrometry using a secondary drift gas. Talanta 73, 692-699 (2007).

4. Cheng, S. et al. Fast switching of $\mathrm{CO}_{3}{ }^{-}\left(\mathrm{H}_{2} \mathrm{O}\right)_{n}$ and $\mathrm{O}_{2}{ }^{-}\left(\mathrm{H}_{2} \mathrm{O}\right)_{n}$ reactant ions in dopant-assisted negative photoionization ion mobility spectrometry for explosives detection. Anal. Chem. 86, 2687-2693 (2014).

5. Tam, M. \& Hill, H. H. Secondary electrospray ionization-ion mobility spectrometry for explosive vapor detection. Anal. Chem. 76, 2741-2747 (2004).

6. Puton, J., Nousiainen, M. \& Sillanpää, M. Ion mobility spectrometers with doped gases. Talanta 76, 978-987 (2008).

7. Oxley, J. C., Smith, J. L., Luo, W. \& Brady, J. Determining the vapor pressures of diacetone diperoxide (DADP) and hexamethylene triperoxide diamine (HMTD). Propellants Explos. Pyrotech. 34, 539-543 (2009).

8. Schulte-Ladbeck, R., Edelmann, A., Quintás, G., Lendl, B. \& Karst, U. Determination of peroxide-based explosives using liquid chromatography with on-line infrared detection. Anal. Chem. 78, 8150-8155 (2006).

9. Marr, A. J. \& Groves, D. M. Ion mobility spectrometry of peroxide explosives TATP and HMTD. Int. J. Ion Mobil. Spectrom. 6, 59-62 (2003).

10. Crowson, A. \& Beardah, M. S. Development of an LC/MS method for the trace analysis of hexamethylenetriperoxidediamine (HMTD). Analyst 126, 1689-1693 (2001)

11. Buttigieg, G. A., Knight, A. K., Denson, S., Pommier, C. \& Bonner Denton, M. Characterization of the explosive triacetone triperoxide and detection by ion mobility spectrometry. Forensic Sci. Int. 135, 53-59 (2003).

12. Soppart, O. \& Baumbach, J. I. Comparison of electric fields within drift tubes for ion mobility spectrometry. Meas. Sci. Technol. 11, 1473-1479 (2000).

13. Langejuergen, J., Cochems, P. \& Zimmermann, S. Results of a transient simulation of a drift tube ion mobility spectrometer considering charge repulsion, ion loss at metallic surfaces and ion generation. Int. J. Ion Mobil. Spectrom. 15, 247-255 (2012).

14. Ilbeigi, V. \& Tabrizchi, M. Peak-peak repulsion in ion mobility spectrometry. Anal. Chem. 84, 3669-3675 (2012).

15. Jafari, M. T., Saraji, M. \& Sherafatmand, H. Design for gas chromatography-corona discharge-ion mobility spectrometry. Anal. Chem. 84, 10077-10084 (2012).

16. Xu, J., Whitten, W. B. \& Ramsey, J. M. Pulsed-ionization miniature ion mobility spectrometer. Anal. Chem. 75, 4206-4210 (2003).

17. Liang, X. et al. Sensitive detection of black powder by a stand-alone ion mobility spectrometer with an embedded titration region. Anal. Chem. 85, 4849-4852 (2013).

18. Liu, X., Li, S. \& Li, M. Optimization design of drift tube for ion mobility spectrometer based on simulation of drift electric field. Int. J. Ion Mobil. Spectrom. 15, 231-237 (2012).

19. Davila, S. J., Hadjar, O. \& Eiceman, G. A. Ion profiling in an ambient drift tube-ion mobility spectrometer using a high pixel density linear array detector ionCCD. Anal. Chem. 85, 6716-6722 (2013).

20. Kwasnik, M., Fuhrer, K., Gonin, M., Barbeau, K. \& Fernández, F. M. Performance, resolving power, and radial Ion distributions of a prototype nanoelectrospray ionization resistive glass atmospheric pressure ion mobility spectrometer. Anal. Chem. 79, 77827791 (2007).

21. Sukumar, H., Davila, S. J. \& Eiceman, G. A. Patterns of ion distributions from a cylindrical ${ }^{63} \mathrm{Ni}$ foil in an ion mobility spectrometer. Int. J. Ion Mobil. Spectrom. 17, 139-145 (2014).

22. Tang, X., Bruce, J. E. \& Hill, H. H. Characterizing electrospray ionization using atmospheric pressure ion mobility spectrometry. Anal. Chem. 78, 7751-7760 (2006).

23. Tabrizchi, M., Khayamian, T. \& Taj, N. Design and optimization of a corona discharge ionization source for ion mobility spectrometry. Rev. Sci. Instrum. 71, 2321-2328 (2000).

24. Karpas, Z. et al. Ion distribution profiles in the drift region of an ion mobility spectrometer. Int. J. Mass Spectrom. Ion Processes 127, 95-104 (1993).

25. Wu, C. et al. Construction and characterization of a high-flow, high-resolution ion mobility spectrometer for detection of explosives after personnel portal sampling. Talanta 57, 123-134 (2002).

26. Spangler, G. E. Expanded theory for the resolving power of a linear ion mobility spectrometer. Int. J. Mass Spectrom. 220, 399418 (2002).

27. Puton, J. \& Siodłowski, B. Generation of current pulses in collector electrode of IMS detectors. Int. J. Mass Spectrom. 298, 55-63 (2010).

28. Du, Y., Wang, W. \& Li, H. Bradbury-Nielsen-gate-grid structure for further enhancing the resolution of ion mobility spectrometry. Anal. Chem. 84, 5700-5707 (2012).

29. Schaefer, W. P., Fourkas, J. T. \& Tiemann, B. G. Structure of hexamethylene triperoxide diamine. J. Am. Chem. Soc. 107, 24612463 (1985).

30. Peng, L., Hua, L., Wang, W., Zhou, Q. \& Li, H. On-site rapid detection of trace non-volatile inorganic explosives by stand-alone ion mobility spectrometry via acid-enhanced evaporization. Sci. Rep. 4, 6631-6635 (2014).

31. Blanco, G. A. et al. Identification of inorganic improvised explosive devices using sequential injection capillary electrophoresis and contactless conductivity detection. Anal. Chem. 83, 9068-9075 (2011).

\section{Acknowledgements}

This work is partly supported by National High-Tech Research and Development Plan (No. 2014AA06A501), Natural Science Foundation of China (No. 21177124, 71433006, 71373117), National Key Scientific Instrument and Equipment Development Project (No. 2013YQ090703).

\section{Author Contributions}

Q.Z. performed the experiments, analyzed data and wrote this paper; L.P. prepared the inorganic explosive samples; D.J. carried out the synthesis and treatment of HMTD; X.W. prepared the TNT solutions and contributed to the discussion of results; H.W. and H.L. were owners of the foundations supporting this study. H.L. also conducted the experiments and the refinement of this paper.

\section{Additional Information}

Supplementary information accompanies this paper at http://www.nature.com/srep 
Competing financial interests: The authors declare no competing financial interests.

How to cite this article: Zhou, Q. et al. Detection of Nitro-Based and Peroxide-Based Explosives by Fast Polarity-Switchable Ion Mobility Spectrometer with Ion Focusing in Vicinity of Faraday Detector. Sci. Rep. 5, 10659; doi: 10.1038/srep10659 (2015).

(c) (i) This work is licensed under a Creative Commons Attribution 4.0 International License. The images or other third party material in this article are included in the article's Creative Commons license, unless indicated otherwise in the credit line; if the material is not included under the Creative Commons license, users will need to obtain permission from the license holder to reproduce the material. To view a copy of this license, visit http://creativecommons.org/licenses/by/4.0/ 